\title{
A Rare Case of Localized Tetanus
}

\author{
Deepak S. Sharma, Mit B. Shah \\ Department of Intensive Care Medicine, Shree Krishna Hospital, Karamsad, Anand, Gujarat, India
}

\section{Abstract}

Tetanus is a severe and potentially fatal infection caused by the bacterium Clostridium tetani. Presentations of tetanus include generalized tetanus, neonatal tetanus, cephalic tetanus, and localized tetanus, the latter two being much rarer. We present case of a 55-year-old male farmer, presented with an injury to the left toe. A surgical wound exploration and washout with administration of human tetanus immunoglobulin and tetanus toxoid were given as treatment with antibiotic support. This case report points out the importance of the early recognition of a rare form of this fatal infectious disease, which may present with prodromal symptoms before the generalized form shows its clinical effects. Successful management includes prompt diagnosis, neutralization of circulating toxin and elimination of C. tetani infection, control of spasms, maintenance of the airway, and management of respiratory failure and autonomic dysfunction.

Keywords: Localized tetanus, tetanus, tetanus immunoglobulin

\section{INTRODUCTION}

Tetanus is a life-threatening and serious infectious disease with a high morbidity and mortality if left untreated. ${ }^{[1]}$ Clostridium tetani is a gram-positive bacillus producing tetanospasmin, the toxin leading to its disabling and fatal manifestations. ${ }^{[2]}$ Generalized tetanus is the most classical form. However, atypical patterns of presentation including cephalic and rarely localized tetanus may prove to be difficult diagnoses to arrive to, in view of its unusual presentation. ${ }^{[3]}$ Looking into the journals and scientific literature, we can find very few publications related to localized tetanus in human. Hence, this case report becomes important to impart knowledge to treating doctors in Intensive Care Units to learn features of localized tetanus for early recognition and need for prompt diagnosis and treatment.

\section{Case Report}

A 55-year-old male farmer presented with history of an injury to the left toe 7 days before presentation, followed by recent onset of fever, chills, and headache [Figure 1]. He took treatment with a local doctor and within $24 \mathrm{~h}$ developed complaints of pain in the left lower limb associated with intermittent muscle spasms involving left lower limbs [Figure 2]. On complete neurological examination, there were no features of bowel/bladder involvement, alteration of sensorium, or signs of generalized tetanus such as trismus (lockjaw), muscle pain and

\begin{tabular}{|l|l|}
\hline \multicolumn{3}{c|}{ Access this article online } \\
\hline Quick Response Code: & Website: \\
& www.ijccm.org \\
\hline
\end{tabular}

stiffness, back pain, opisthotonus, or difficulty in swallowing. He did not have any history of immunization. Furthermore, he did not give any history of ingestion of poisonous substances or any alternative medications. On laboratory blood investigations, he was found to have leukocytosis, with normal renal and liver function with elevated C-reactive protein. Radiographic imaging of the hip, knee, and ankles of the right and left limbs was normal. In view of spasmodic contractions localized mainly to the left lower limb, a prompt diagnosis of localized tetanus was made and immediately human tetanus immunoglobulins, 1000 IU IM, were given to the patient to neutralize the circulating toxins. Surgical management of the wound was carried out urgently, along with administration of tetanus toxoid (TT). For muscle spasm, diazepam infusion of $1 \mathrm{mg} / \mathrm{kg}$ /day was given with which his spasm subsided and was tapered within 3 days and switch to oral form. He did not have any further worsening. He did not require tracheostomy since spasm did not generalize. Cephalosporin and metronidazole were given as antibiotic coverage. He was discharged in 7 days and has been followed up to look for response. He is stable, with no residual deficit on 6-month follow-up.

Address for correspondence: Dr. Deepak S. Sharma, Bunglow 73, Shanti Villa, Sargasan, Gandhinagar - 382 421, Gujarat, India. E-mail: deepu84in@gmail.com

This is an open access journal, and articles are distributed under the terms of the Creative Commons Attribution-NonCommercial-ShareAlike 4.0 License, which allows others to remix, tweak, and build upon the work non-commercially, as long as appropriate credit is given and the new creations are licensed under the identical terms.

For reprints contact: reprints@medknow.com

How to cite this article: Sharma DS, Shah MB. A rare case of localized tetanus. Indian J Crit Care Med 2018;22:678-9. 


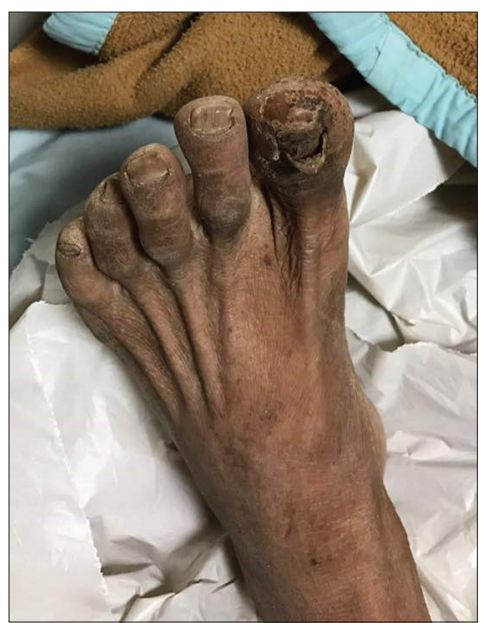

Figure 1: Left toe wound

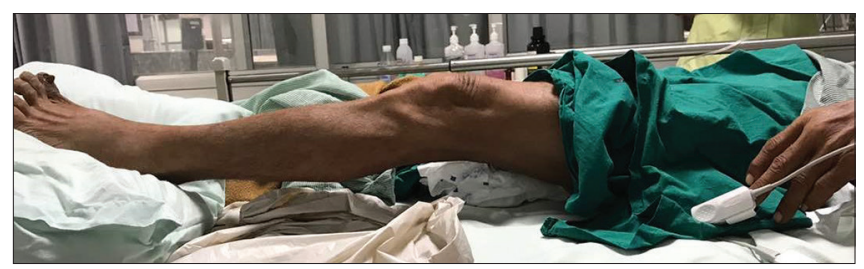

Figure 2: Muscle spasm involving left lower limb

\section{Discussion}

C. tetani is an anaerobic bacterium found commonly in soil in spore form or in the gastrointestinal tracts of mammals and produces a potent neurotoxin, tetanospasmin. Incubation period ranges from 3 to 21 days, with most average incubation period being 10 days. Tetanospasmin causes violent spastic paralysis by blocking the release of $\gamma$-aminobutyric acid, inhibitory neurotransmitter acting on motor neurons. ${ }^{[3]}$

Localized tetanus is rarely reported in literature, and to the best of our knowledge, only three to four cases of localized tetanus have been reported in the last decade. ${ }^{[3,4]}$ The diagnosis of tetanus is mainly clinical, which may not be difficult in a case of generalized tetanus. However, a case of localized or cephalic tetanus has a varied presentation and may be difficult to distinguish from a local disorder involving the joints or a hysterical disorder. ${ }^{[3]}$

A retrospective analysis done in 2001 by Kakou et al. showed a cure rate of $82 \%$ with $16 \%$ mortality in 37 cases reported of tetanus in the last 22 years. ${ }^{[3]}$
In another case report, a child had developed localized tetanus following immune globulin injection and was managed with TT immunoglobulin and intravenous benzylpenicillin and recovered within 2 weeks. ${ }^{[3]}$ Furthermore, there have been case reports of localized tetanus in cats with recovery with supportive therapy. ${ }^{[5]}$

Localized tetanus has a good cure rate generally, and hence, aggressive management is required to prevent generalization. Management principles include neutralization of the toxin with tetanus immunoglobulin, as well as debridement of the wound. Choice of antibiotic is metronidazole. An alternative is penicillin (100,000-200,000 IU/kg/day), although it may exacerbate spasms. ${ }^{[6]}$

The patient should be given a complete primary course of immunization, as tetanus toxin is poorly immunogenic and the immune response following natural infection is inadequate. ${ }^{[6]}$

\section{Declaration of patient consent}

The authors certify that they have obtained all appropriate patient consent forms. In the form, the patient has given his consent for his images and other clinical information to be reported in the journal. The patient understands that name and initial will not be published and due efforts will be made to conceal identity, but anonymity cannot be guaranteed.

\section{Financial support and sponsorship}

Nil.

\section{Conflicts of interest}

There are no conflicts of interest.

\section{RefERences}

1. Afshar M, Raju M, Ansell D, Bleck TP. Narrative review: Tetanus-a health threat after natural disasters in developing countries. Ann Intern Med 2011;154:329-35.

2. Malik R, Church D, Maddison J, Farrow B. Three cases of local tetanus. J Small Animal Pract 1989;30:469-73.

3. Gupta V, Dewangan S, Dev Bhatia B. Localised tetanus: Rare presentation of a 'forgotten' disease. J Paediatr Child Health 2011;47:152.

4. Kakou AR, Eholie S, Ehui E, Ble O, Bissagnene E, Aoussi E, et al. Localized tetanus in Abidjan: Clinical and prognostic features (1976-1997). Bull Soc Pathol Exot 2001;94:308-11.

5. Polizopoulou ZS, Kazakos G, Georgiadis G, Soubasis N, Koutinas Ch, Koutinas AF, et al. Presumed localized tetanus in two cats. J Feline Med Surg 2002;4:209-12.

6. Louise Thwaites C, Yen LM. Tetanus. In: Kasper DL, editor. Harrison's Principles of Internal Medicine. $19^{\text {th }}$ ed. New Delhi: McGraw-Hill Education; 2015. p. 984-6. 